\title{
As Teias que a Doença Tece: A Análise das Redes Sociais no Cuidado da Doença Mental
}

\author{
Sílvia Portugal ${ }^{1}$ \\ Cláudia Nogueira ${ }^{1}$ \\ Pedro Hespanha \\ ${ }^{1}$ Universidade de Coimbra, Coimbra, Portugal. E-mail: sp@fe.uc.pt.
}

\section{INTRODUÇÃO}

\begin{abstract}
implementação das reformas psiquiátricas e da filosofia de A desinstitucionalização impõe uma análise dos modelos de resposta ao cuidado da doença mental, discutindo potencialidades e constrangimentos. Este artigo pretende contribuir para esse objetivo, construindo uma abordagem a partir da teoria das redes. Segundo Wellman (1985), esta permite uma "análise relacional" que estuda o modo como os indivíduos são condicionados pelo tecido social que os envolve, mas, também, a forma como eles o utilizam e modificam conforme seus interesses. Neste texto pretendemos explorar esta possibilidade e analisar, por um lado, a maneira como as redes sociais são influenciadas pela doença mental e, por outro, a sua influência nas trajetórias pessoais e clínicas das pessoas com doença mental, mostrando a relevância desta perspectiva para olhar os modelos de cuidado da doença. Para que desinstitucionalização não signifique desassistência, é fundamental mapear atores e identificar recursos disponíveis, percebendo as suas articulações, capacidades de resposta e limitações. Uma abordagem a partir da análise de redes permite responder a este desafio (Fontes e Portugal, 2013).
\end{abstract}

Wasserman e Faust identificam quatro princípios fundamentais na teoria das redes sociais: 1) os atores e as suas ações são vistos como in-

DADOS - Revista de Ciências Sociais, Rio de Janeiro, vol. 57, no-4, 2014, pp. 935 a 968. 
terdependentes e não como unidades independentes e autônomas; 2) os laços relacionais entre os atores são canais onde circulam fluxos de recursos (materiais e imateriais); 3) os modelos de rede centrados nos indivíduos concebem as estruturas de relações como meios que configuram oportunidades ou constrangem a ação individual; 4) os modelos de rede conceitualizam a estrutura (social, econômica, política etc.) como padrões constantes de relações entre atores (Wasserman e Faust, 1999:4).

Uma rede social pode ser definida como "um conjunto de unidades sociais e de relações, diretas ou indiretas, entre essas unidades sociais, através de cadeias de dimensão variável" (Mercklé, 2004:4). De uma forma operacional, a análise a partir das redes sociais pode sintetizar-se em algumas questões muito simples: Quem? O quê? Como? Quem faz parte das redes? Quais os conteúdos dos fluxos das redes? Quais as normas que regulam a sua ação? (Portugal, 2007).

Neste artigo interessa-nos caracterizar, simultaneamente, a morfologia das redes e os conteúdos dos fluxos que circulam no seu interior quais são os elementos da rede? Que características apresentam as redes sociais das pessoas com doença mental? Que tipos de apoio são prestados pelos diferentes elementos? A que recursos acedem os indivíduos através dos seus laços?

O artigo apresenta alguns resultados de uma pesquisa sobre a desinstitucionalização da doença mental, as trajetórias de vida e os itinerários terapêuticos das pessoas com doença mental ${ }^{1}$. A análise aqui apresentada centra-se nas histórias de vida de 20 pessoas com doença mental e em sete estudos de caso realizados a partir desse grupo. Apesar de a análise de redes, em geral, privilegiar uma análise quantitativa, a pesquisa propôs uma abordagem qualitativa, centrada no caráter dinâmico das redes, na interação e no diálogo entre os atores. A técnica privilegiada do estudo foi, assim, a entrevista em profundidade.

As 20 pessoas entrevistadas foram escolhidas através do seu contato com um hospital psiquiátrico ${ }^{2}$, de modo a incluir diferentes situações clínicas e diferentes experiências de institucionalização e de contato com a realidade hospitalar ${ }^{3}$. O estudo das trajetórias dessas pessoas envolveu o conhecimento das suas relações com a instituição hospitalar, com os serviços de saúde locais e com outros prestadores de cuidados institucionais ou informais. 
A seleção das pessoas com doença mental foi realizada em função da sua patologia e de variáveis sociográficas. A doença mental apresenta-se sob um muito diverso número de formas nosológicas a que correspondem, também, diferentes graus de severidade. A severidade e a cronicidade são fatores que, pela sua relação com a prestação de cuidados, mais facilmente podemos associar à institucionalização. Por essa razão, entendeu-se centrar a análise nas patologias com maior grau de severidade e cronicidade, sem perder de referência patologias menos severas e situações de ocorrência aguda, designadamente quando elas confluem nas biografias dos doentes. Neste quadro, a esquizofrenia e a doença bipolar apareceram como as opções mais adequadas aos fins da pesquisa ${ }^{4}$.

Em método de bola de neve, estas pessoas conduziram-nos aos seus agregados familiares e às suas redes sociais, formais e informais. Foram, assim, realizados sete estudos de caso, que corresponderam a 28 entrevistas (entre duas e oito pessoas por caso) a elementos das redes sociais dos indivíduos - familiares, amigos, colegas, vizinhos, técnicos.

A análise proposta neste artigo pretende contribuir para a construção de abordagens teóricas e metodológicas que tenham em conta a complexidade das trajetórias pessoais e clínicas das pessoas com doença mental e a diversidade de atores nelas presentes. Os modos como se entende, explica e lida com a doença mental dependem de uma multiplicidade de atores, das suas práticas e representações. Usando conceitos e metodologias da teoria das redes, este estudo pretende fazer um mapeamento desses atores. Centra, no entanto, a sua análise apenas no papel das relações informais, deixando de fora as relações estabelecidas no âmbito institucional e formal ${ }^{5}$.

Partindo de uma abordagem egocentrada ${ }^{6}$, identificam-se os nós e os laços das redes - os elementos das redes e as relações que entre eles se estabelecem - e, a partir da sua caracterização, identificam-se algumas propriedades morfológicas das redes, das quais se destacam as seguintes: a) dimensão - número de elementos que constituem a rede; b) densidade - relação entre os laços ativados e o total de potenciais membros da rede; c) orientação - as relações orientam-se preferencialmente para certas pessoas (parentes, amigos, vizinhos, colegas?). No que diz respeito à rede de parentesco, as relações estabelecem-se preferencialmente num sentido vertical ou horizontal (privilegiam-se os parentes 
em linha reta ou os colaterais?); d) polarização - atores que desempenham um papel de "catalisadores de relações", por quem passam os laços estabelecidos entre os diferentes membros da rede; e) sobreposição ou dissociação - um laço pode ter mais do que um conteúdo. Os diferentes elementos da rede podem desempenhar mais do que um papel no total da rede; f) segmentação - os elementos que pertencem a diferentes redes (parentesco, amizade, vizinhança, profissionais) interagem entre si ou constituem núcleos de relações independentes.

Mapeiam-se, assim, os atores ativos na prestação de cuidados, de modo a conhecer a capacidade de resposta das redes sociais, o tipo de apoio prestado e as necessidades sentidas, fornecendo, desta forma, elementos para a identificação dos fatores que bloqueiam ou facilitam a implementação da filosofia de desinstitucionalização.

\section{OS NÓs}

O traço mais marcante da morfologia das redes sociais das pessoas entrevistadas é a sua orientação para os laços de parentesco e, no seu interior, para o parentesco restrito. Se esta é, de um modo geral, uma característica das redes sociais em Portugal (Portugal, 2014), na população entrevistada essa característica é ainda mais acentuada. $\mathrm{O}$ fechamento das redes produzido pela doença acentua a demarcação entre "a família" e "os outros". Os nós familiares representam segurança, permanência, confiança. Por oposição, os "outros" laços estabelecidos fora do parentesco são alvo de desconfiança e insegurança, e os relatos de desilusões com amigos, colegas e vizinhos são muito mais frequentes do que aqueles que se referem aos parentes. Os "outros" desaparecem quase todos com o poder disruptivo da doença, enquanto os parentes tendem a permanecer e a resistir.

\section{A Família}

Os nós da família restrita - pais, irmãos, cônjuges, filhos - são os principais agentes de cuidados informais. Dependendo do ciclo de vida e da sua situação conjugal, a maioria dos(as) entrevistados(as) tem na sua família de origem e/ou na família conjugal o seu principal suporte.

Em geral, a família de origem é a principal cuidadora. O apoio faz-se sobretudo no sentido vertical descendente - os pais, essencialmente as mães, são os nós mais ativos na prestação de apoio. O seu papel é crucial para as trajetórias pessoais e sociais dos indivíduos e na manuten- 
ção da vida cotidiana. Os laços parentais caracterizam-se pela sua continuidade e pela diversidade de apoios prestados ao longo do ciclo de vida. "Sempre foi lutadora [a mãe] e... [pausa] e que sempre nos ajudou. Apesar de eu estar mal, não é? Numa certa altura, pronto, por causa de drogas e essas coisas. Ela nunca me abandonou e sempre me ajudou e eu estou-lhe grato por isso. Porque para mim é uma grande mulher, além de ser mãe" (Ricardo).

Quando as pessoas vivem ou viveram em situações de conjugalidade, a família conjugal tende a substituir o papel assumido pela família de origem, assegurando a maioria dos apoios necessários. A importância dos ascendentes, no entanto, tende a manter-se, em articulação com os laços de aliança. Essa importância é tanto maior quanto se verifica existir uma incapacidade da família conjugal para lidar com os efeitos da doença - incapacidade decorrente do esgotamento emocional ou da relativa falta de preparação, quando a relação de conjugalidade é ainda recente.

Quanto mais precoce é a manifestação de sintomas da doença, mais difícil é as pessoas experienciarem situações de conjugalidade. A vida afetiva é uma das áreas na qual o impacto da doença nas redes sociais se revela com maior violência. Os relatos de solidão e incompreensão abundam nas histórias de vida destas pessoas. "Mesmo homens, nunca... Conheci aqui alguns e tenho os telemóveis, o número de telemóveis deles, mas... não... nunca mais. Nem quis fazer vida afetiva. Tenho uma vida afetiva quase nula em relação ao sexo oposto. Não sei por que, mas pronto" (Iolanda).

Dos entrevistados, apenas dois homens e quatro mulheres são casados(as) e/ou vivem em união de fato. Dos homens solteiros, vários nunca tiveram qualquer relação amorosa. Três das mulheres são divorciadas. Os relatos de rupturas amorosas causadas pela doença são frequentes. Dificilmente os(as) parceiros(as) resistem às adversidades originadas pela doença - aos comportamentos de quem está doente, às exigências clínicas e terapêuticas, ao estigma social, aos problemas materiais, aos conflitos. No entanto, as rupturas matrimoniais são menos frequentes. Quando a doença se manifesta já num contexto de vivência da conjugalidade, as relações revelam enorme resistência às dificuldades. Nos casos em que as pessoas vivem em conjugalidade, o cônjuge torna-se um nó crucial, o laço mais forte e mais ativo na prestação de apoio, desempenhando um papel central no enfrentamento da doença e na integração social. 
A minha mulher tem sido um pilar. [Pausa] Eu queria ver se arranjava algum adjetivo... Se eu disser que a minha mulher tem sido um pilar fundamental, é pouco.

É pouco...

É pouco. Portanto, já percebe o que eu quero dizer. Eu até diria mais. Eu até diria mais. Arrisco... Arrisco... Eu arrisco a dizer que qualquer outra mulher, no lugar dela, já se tinha ido embora há muito tempo. Não tenho grandes dúvidas; qualquer outra mulher... E, no entanto, aconteceu justamente o contrário. Eu é que já disse $\mathrm{N}$ vezes... $\mathrm{N}$ vezes que me ia embora. Qualquer outra mulher no lugar dela já se tinha ido embora há muito tempo. Muito tempo. Nunca... Não aturaria um décimo do que ela tem aturado. Com... Sempre presente, sempre presente. Sempre com uma palavra amiga, sempre a meu lado... Sempre a fazer tudo o que está ao alcance dela para melhorar; sempre a tentar que eu tente... Sempre a tentar que eu arranje alternativas; sempre a dar-me a mão; sempre a fazer-me os melhores pratos... (Vasco).

Às vezes, eu digo que ele é mais meu pai do que meu marido. É, porque ele olha para mim como se eu fosse se calhar uma filha para ele. Que eu às vezes vejo coisas que ele tem... Ele é muito cuidadoso comigo. Ele, quando estive doente, ainda sofreu mais do que eu. Ele ainda sofreu mais do que eu. [silêncio] [...] Ele tem um amor por mim... eu não... não sei explicar. Faz coisas que não dá para explicar. Que nunca ninguém me fez. Mas eu também não consigo demonstrar essas coisas (Helena).

Vale lembrar que no conjunto de pessoas que entrevistamos, apenas duas têm filhos em idade adulta e, em ambos os casos recebem deles forte apoio material e emocional. A família nuclear parece, assim, ser uma fonte crucial de suporte, ampliando a rede social para além da família de origem.

Em relação aos meus filhos, a minha filha é dócil, a minha filha é um amor, a minha filha é... a minha filha é... tem um coração do tamanho do mundo; é dócil, é meiga, é afetuosa, é... Quando eu me fechava ali num quarto, no quarto das visitas; quando eu me fechava lá dois e três dias, era ela que conseguia que eu comesse alguma coisa, era ela que conseguia conversar comigo, mais ninguém (Vasco).

\section{A Família Alargada}

De um modo geral, não encontramos laços ativos na prestação de apoio no interior da família alargada, e raros são os casos em que os pa- 
rentes afastados estão presentes no cotidiano das pessoas com doença mental.

Iolanda retrata uma exceção:

Tenho tios, tenho dois tios. Tenho tios da parte do meu pai que são emigrantes, praticamente nunca os vejo. Então, depois de os filhos casarem, de os meus primos casarem nunca mais houve ligação. Mesmo quando eles cá estão não nos procuram também. Da parte da minha mãe, tenho uma tia que não tem filhos e que é casada. Com eles temos também uma ligação muito forte. E a minha mãe pensa que um dia, quando falecer, eu encontro mais apoio sobretudo na minha tia do que no meu irmão, porque o meu irmão não pode estar tão disponível.

No entanto, embora a maioria das pessoas entrevistadas não tenha laços fortes com a família alargada, esta tende a representar, tal como acontece para o conjunto da população (Portugal, 2014), uma referência afetiva, que constrói uma identidade coletiva, um "nós" de referência identitária - tios, tias, primos e primas tecem uma teia que não é ativa nos apoios, que não está presente no cotidiano, mas "está lá" e representa uma retaguarda de apoio, se não diretamente para as pessoas com doença mental, pelo menos para os seus familiares diretos, sendo este um papel importante.

Para além desta função simbólica, a importância dos parentes afastados é diminuta. Os contatos são esporádicos e a relação da família restrita com a família alargada não difere muito da que se constrói com elementos fora do parentesco. A doença fecha a família ao exterior, sente-se a mesma incompreensão dos parentes e dos outros, esconde-se deles a dor e o sofrimento.

\section{Os "Outros"}

Como já foi dito, os laços ativos fora do parentesco restrito são escassos nas redes sociais das pessoas com doença mental. A relação com amigos, colegas e vizinhos é marcada pelo estigma, que fecha as redes e isola a pessoa doente.

As relações com os "outros" fora da família distinguem-se pelo grau de liberdade que a sua escolha comporta. As relações com os parentes são muito mais sujeitas a constrangimentos sociais do que as relações com os outros. Os nós da rede fora dos laços de parentesco são menos permanentes no tempo, mais efêmeros. Os parentes são os mesmos toda a 
vida; os amigos, os conhecidos, os vizinhos, os colegas vão mudando ao longo do ciclo de vida. Os amigos não têm regras claras de associação, não estão sujeitos às mesmas obrigações e responsabilidades dos parentes. Os laços de amizade são muito mais livres do que os de parentesco. E é nessa liberdade que se jogam as suas vantagens e desvantagens: o preço da escolha livre é o risco da perda do laço, que não existe na relação de parentesco (Portugal, 2014).

De um modo geral, o que os relatos das pessoas entrevistadas revelam é que, perante a doença, a escolha dos laços fora do parentesco é sair da relação. Poucos têm capacidade para lidar com os sintomas e manifestações da doença, a incompreensão é generalizada, o medo, comum, a intolerância, uma constante. As reações negativas e a rejeição social são ainda maiores e tornam-se uma constante após as experiências de internamento hospitalar, que têm um enorme impacto na desestruturação dos laços sociais. Ao estigma da doença é acrescido o do hospital psiquiátrico. A "morte social" de que fala Goffman (2001) para descrever a vida dos doentes institucionalizados estende-se, assim, para além das paredes do hospital. As trajetórias dos entrevistados revelam como os muros se erguem na vida cotidiana - as relações sociais fora do parentesco são dominadas pelo estigma da doença, as pessoas doentes são excluídas dos círculos sociais de sociabilidade e amizade e remetidas para o fechamento do espaço familiar.

\section{Os Amigos}

Os amigos são nós escassos nas redes das pessoas com doença mental. Por um lado, encontramos aqueles que nunca construíram laços ativos de amizade ao longo do seu percurso de vida, tendo uma rede social totalmente orientada para a família; por outro, temos os que, ao verem a doença manifestar-se num período mais tardio do ciclo de vida, perderam os amigos que tinham. Os relatos de abandono dos laços de amizade perante a doença são comuns. Frequentemente, esse abandono é protagonizado pela própria pessoa, em virtude da incapacidade para a interação social provocada pela doença.

Nesse ano senti-me muito isolado, muito... muito... Eu separava-me das pessoas. Não era isolado. Eu separava-me das pessoas.

Afastava-se.

Afastava-me. Não me sentia em condições de estar a interagir com ninguém. Sentia medo. Sentia medo, não sei... Mas antes disso era... Antes disso, eu costumo dizer que antes dos 18 anos ninguém me parava. Por- 
que eu, pronto, eu... era extrovertido, falava com toda a gente, era simpático com toda a gente, não fazia mal a ninguém... Pronto, e depois a doença fez-me... (Paulo).

As entrevistas revelam a dificuldade que as pessoas têm em atribuir o estatuto de "amigo" a alguém. A desconfiança para com as relações de amizade é grande e aparece como contraponto à confiança nas relações familiares. Se, na população em geral, existe uma ideia generalizada de que as verdadeiras amizades só se reconhecem quando postas à prova (Portugal, 2014), entre as pessoas entrevistadas este princípio parece ser absolutamente estruturador das redes - a doença "filtra" as amizades. Ela é o "momento da verdade" - só restam aqueles que são merecedores de confiança e resistem a todas as adversidades.

Apesar da escassez de laços de amizade na morfologia das redes das pessoas com doença mental, aquelas que os identificam mostram-se extremamente gratificadas com estas relações. Pelo grau de liberdade que comportam, pela ausência de obrigação, por "só ficarem porque querem", os laços de amizade quando existem e "dão provas", são muito valorizados e pontos de apoio e referência cruciais. Estes elementos prestam algumas ajudas materiais, mas, essencialmente, apoio afetivo. Os amigos são fonte de sociabilidade, conversam, obrigam a sair do espaço doméstico, transmitem confiança e segurança.

Eu na altura... uma altura que perdi a noção das coisas. Deixei de conhecer as pessoas, deixei... Cheguei a pôr açúcar no arroz..., sal num bolo. Mas ela... Nunca aquela rapariga [amiga]... nunca me disse que estava mal feito. O primeiro bolo que eu fazia, levava-lhe uma fatia. Um doce que eu fazia, levava-lhe. Tanto que ela considera-me como irmã dela e eu considero-a como minha irmã. Tenho mais abertura com ela do que com a minha irmã (Helena).

\section{Os Colegas}

Na população em geral existem dois tipos de colegas: os colegas de escola e os de trabalho. A escola e o trabalho são os locais onde as pessoas estabelecem a maioria dos laços exteriores à família. A importância e a evolução dessas relações depende, em grande parte, do tipo de percurso escolar e do tipo de trabalho desempenhado (Portugal, 2014). Para as pessoas que entrevistamos, os nós da rede que identificam como "colegas" são, sobretudo, colegas de trabalho. Raros são aqueles que mencionam colegas de escola como elementos das suas redes. Se por 
um lado este dado se justifica pelos reduzidos percursos escolares da maioria dos(as) entrevistados(as), por outro, os relatos revelam sempre trajetórias solitárias com escassas sociabilidades em contexto escolar.

Estes laços com colegas de trabalho surgem nas redes daqueles(as) para quem a doença surgiu já num contexto de inserção na vida ativa. Os relatos acerca destas relações são muito semelhantes aos que encontramos a respeito dos laços de vizinhança - a incompreensão e a intolerância dominam. Os contextos laborais são extremamente adversos à integração destas pessoas - os sinais da doença são mal compreendidos, os problemas no trabalho atribuídos a falhas pessoais, as baixas e faltas médicas consideradas desnecessárias e vistas como abusivas.

Tanto até... que isto começou a piorar. Eram internamentos... Depois ia para o Sobral Cid [hospital psiquiátrico], chegava lá... vinha... Estava lá três semanas, um mês..., vinha. Mandavam-me ir trabalhar. Chegava lá: Tumba. Outra vez. Mais internamentos. Chegaram a um ponto que já não me mandavam trabalhar mais. Depois tinha uma coisa: os encarregados na firma não me ajudavam em nada. Os encarregados a mim só me... ainda me enterravam mais, porque eu... Na vez de me ajudarem... viam que eu estava a... a ficar doente, não... Eu estava habituado lá nessa firma a trazer... A minha máquina..., por exemplo, com que eu trabalhava, o chão dela podia-se lamber com a língua que andava sempre tudo limpinho. Gostava da máquina sempre a brilhar. Eu gosto... Tinha aquilo tudo sempre que era um brinco. Então, o encarregado, a pensar que eu estava a fazer as coisas com malandrice, tirou-me a minha máquina e deu-me uma máquina muita podre, muita velha, cheia de lixo, toda porca... Então aí, muito... mais mal me senti. Estava habituado à minha máquina, sabia como é que eu tinha e como é que... Eu via os outros a trabalhar com ela e eu a andar com aquilo... Ficava... Então aí é que começou a internar (Francisco).

Apesar de esta ser a tendência generalizada, encontramos também, entre os casos analisados, pessoas que estabelecem laços fortes com colegas de trabalho. Estes são, em geral, laços ativos na prestação de apoio emocional e um fator importante para a manutenção do posto de trabalho e o enfrentamento das adversidades.

Agora, mesmo a nível do trabalho, todos compreenderam o que se estava a passar, principal... Aliás, foi no trabalho, os meus amigos é que...e as minhas colegas é que chamaram a atenção ao meu pai para aquilo 
que se estava a passar. Portanto, acho que eles também compreenderam bem o que se estava a passar e eles são do tipo que veem: quando a pessoa não está bem, eles notam. Porque eu, ainda agora desta última vez, tive lá colegas que me disseram para mim: "Carolina, não te deixes ir agora abaixo". Pronto, sempre me ajudaram, sempre me deram apoio (Carolina).

Mesmo quando os contextos laborais são mais adversos e o estigma predomina, a inserção no mercado de trabalho é extremamente importante para o estabelecimento de redes sociais e para a ampliação do capital relacional das pessoas com doença mental, contribuindo decisivamente para a sua integração social.

Ajudou-me [o trabalho de apoio domiciliário a idosos] num aspecto, acho que foi mais fácil passar o tempo, porque sinto-me útil ajudando as outras pessoas. Acho que é uma maneira, enquanto há pessoas que procuram fazer voluntariado, eu faço isso no meu trabalho e acabo por fazer voluntariado também, porque às vezes é um gesto, um... Não é só... O apoio domiciliário não se limita só a tratar deles. É também a dar apoio moral, a conversar com eles, a dizer que tem ali alguém [com] quem podem contar. Eu acho que isso também faz parte do apoio, não é? Também tem a ver com a nossa parte humana, o nosso ser humano. É nesse aspecto que eu gosto do apoio, porque trabalhamos com pessoas, não é, não é com uma máquina (Matilde).

\section{Os Colegas de Hospital}

Os laços com pessoas que se conheceram no hospital são identificados pelos usuários do Hospital de Dia. Estes nós revelam-se bastante importantes para a redefinição e ampliação das redes sociais das pessoas entrevistadas.

A classificação destes nós como "colegas" revela a sua característica institucional. Os laços estabelecidos no contexto hospitalar são relevantes por duas razões fundamentais: em primeiro lugar, eles são laços positivos de identificação. Para muitas pessoas, a convivência com outras com os mesmos problemas tem uma enorme importância simbólica - é a primeira vez que têm contato com alguém que compreende o significado de ouvir vozes, de ter alucinações, de não conseguir controlar os impulsos. Em segundo lugar, permite uma renovação das redes sociais, a ampliação do capital relacional, através do estabeleci- 
mento de novos laços. Estes laços são fortes e fracos, dependendo das proximidades afetivas e das similitudes de estatutos e percursos de vida. Os laços com os colegas do hospital são, sobretudo, prestadores de apoio emocional.

Conheci uma moça ali no $1 . .$. que era... é assistente social, foi... - não, educadora de infância - que estava na 1. E eu assim: "Mas tu... Qual éo teu problema? Também ouvias...?" "Eu ouvia vozes. Está calada, não me fales em mais nada, que eu não ando nada bem." Eu pensava que era a única. Afinal de contas... (Cândida).

Portanto o Hospital de Dia tem esse lado positivo de trazer...

Novas amizades... de pessoas que tiveram... passaram por problemas semelhantes ou idênticos, que têm também problemas mentais. E pronto, quer dizer, unimo-nos mais [hesitação]. Quer dizer, há uma identidade maior com essas pessoas que passaram por aqui do que propriamente com as outras pessoas que eu vejo todos os dias no café, ou que eu vejo no ônibus. Pronto, é "bom dia", "boa tarde" e praticamente mais nada. Estando aqui, há uma espécie de identidade comum, então as pessoas unem-se também umas com as outras porque estão com um problema praticamente idêntico (Iolanda).

Apesar da relevância simbólica e afetiva destes laços, o seu significado na morfologia da rede é complexo. Se, por um lado, a existência destas relações é valorizada muito positivamente pelas pessoas, por outro, elas próprias reconhecem a dificuldade da sua transposição para o "exterior". Existe uma rede "dentro" da instituição e outra "fora". Os seus papéis estão dissociados e os elementos que as compõem não interagem entre si.

Ainda sobre o Hospital de Dia, tem relações de amizade com colegas daqui...?

Tenho. Encontrei... Está aqui agora um desenhador, também como eu. Só que já tem mais idade do que eu e já tem mais experiência que eu. E faz projetos excelentes, fantásticos a 3D, que parecem fotografias... Mas há... há outra coisa que é assim: eu uma vez combinei com um rapaz daqui sair, para irmos beber um café. E o que a gente sentiu é que parecíamos dois estranhos lá fora. Um com o outro. Não sabíamos o que dizer, o que falar, não dizíamos nada. Aqui temos qualquer coisa para falar. Temos um objetivo... um objetivo comum. Lá fora, não... Eu, pelo menos, e acho que ele também se sentiu um estranho. Dois estranhos ali (Paulo). 


\section{A Vizinhança}

Tal como alguns autores já apontaram (Lemieux, 1999), os vizinhos fazem parte das redes sociais quando são parentes ou amigos, mas a vizinhança por si não constitui uma rede. No entanto, existem diferenças entre meios rurais e urbanos, sendo que em contexto rural é mais comum a cooptação de amigos entre a comunidade de vizinhança (Portugal, 2014).

Na população estudada, os laços de vizinhança revelam-se importantes para avaliar o impacto da doença mental nas relações sociais, dado que os vizinhos recebem, por vezes, os primeiros ecos do desencadear da doença - comportamentos bizarros, discussões, agressões. Quer em meio urbano, quer rural, a reação é, em geral, de intolerância, rejeição, rotulagem e afastamento.

Este é um fator com impactos fortes na estruturação das redes sociais das pessoas com doença mental, dado que conduz a processos de autofechamento e autoexclusão, que contribuem decisivamente para a redução das suas redes e do seu capital relacional.

Há pessoas da minha rua que me acham um triste... Porque eu adoeci aos 18 anos e nunca estive $100 \%$ bem e coisas do gênero. Houve uma senhora que no funeral de sétimo dia ou não sei o quê da minha mãe ou do meu avô..., já não sei... o padre disse ou costuma dizer... eu nunca fui à missa, mas naquele dia fui. Estava lá em último. E o padre disse: "Agora se cumprimentem e... e não sei o quê". Essa senhora virou-se para trás, viu-me e cumprimentou-me. A partir daí nunca mais me falou (Paulo).

Apesar de a rejeição ser a norma, encontramos casos em que as relações de vizinhança são fundamentais no apoio às pessoas com doença mental. Em alguns deles, é entre os vizinhos que se constroem laços fortes e ativos na prestação de cuidados. É o caso de Olívia. Perante o esgotamento da família e o seu afastamento, a vizinhança tornou-se o seu grande apoio, dando ajudas materiais e afetivas e mobilizando apoios institucionais.

\section{OS LAÇOS}

Os laços - as relações entre os nós da rede - podem ter características muito diferentes. Um critério fundamental para a caracterização dos laços é a existência ou não de uma relação de parentesco (Portugal, 2007). No entanto, outras distinções são importantes: os laços podem ser po- 
sitivos ou negativos (Lemieux, 1999), fortes ou fracos (Granovetter, 1973, 1982), passivos ou ativos (Milardo, 1988). Estas distinções permitem analisar as fronteiras das redes com o seu ambiente externo, mas também as fronteiras entre subsistemas no ambiente interno das redes (Lemieux, 1999:124).

A força dos laços, analisada nos trabalhos seminais de Granovetter $(1973,1982)$, tem como critérios para a sua avaliação, segundo este autor, a duração da relação (antiguidade da relação e tempo despendido junto), a intensidade emocional, a intimidade e os serviços recíprocos. Degenne e Forsé (1994) acrescentaram um quinto critério: a multiplexidade, ou seja, a pluralidade de conteúdos de troca existente num laço.

Relativamente à diferenciação entre laços positivos e negativos, seguimos, tal como Portugal (2007), a apresentada por Lemieux, que se baseia em trabalhos anteriores de diversos autores e que segue, até certo ponto, as distinções de Simmel (1955) entre laços de identificação e de diferenciação. Os positivos são laços de identificação, através dos quais os atores sociais se consideram membros de uma entidade comum, enquanto os negativos são laços de diferenciação, que fazem os indivíduos demarcarem-se como pertencentes a entidades diferentes. Lemieux acrescenta a estas duas categorias outras duas: os laços mistos, que envolvem elementos positivos e negativos, e os laços neutros ou de indiferença (Lemieux, 1999).

Os laços podem, também, ser ativos ou passivos (Milardo, 1988), ou seja, podem basear-se numa interação face a face frequente ou em laços afetivos que envolvem uma interação irregular. Ambos são importantes no apoio aos indivíduos, mas tendem a operar de maneiras distintas. Os ativos incluem interações rotineiras que, em geral, envolvem ajudas diretas, conselhos e críticas, apoio e interferência. Os passivos, apesar de não envolverem uma interação cotidiana, podem ser igualmente importantes do ponto de vista da segurança individual e familiar - os laços existem e os indivíduos sabem que podem contar com eles quando necessário.

O sentido e a força dos laços prendem-se com propriedades como o conteúdo dos fluxos, sua diversidade, a frequência dos contatos, o tempo despendido na interação e a influência e interferência de um elemento sobre o comportamento do outro. 
Assim, é no interior da rede familiar que encontramos os laços positivos e ativos. Apesar de os amigos e os colegas de hospital serem nós com os quais existe identificação e, portanto, com quem se estabelecem laços positivos, é com os parentes que as pessoas mantêm uma relação de identificação mais clara. É sobretudo com eles que se constroem os laços fortes, ou seja, segundo a definição de Granovetter, com quem se passa mais tempo, se tem uma relação emocional mais forte, se produz uma relação de intimidade e de quem se recebe mais apoio.

É também entre a família restrita que encontramos os laços ativos na prestação de apoio. Os parentes próximos desempenham múltiplos papéis e respondem a múltiplas necessidades materiais e afetivas das pessoas com doença mental, sendo centrais para as suas trajetórias sociais e clínicas.

Laços ativos e passivos são ambos importantes no apoio aos indivíduos, mas operam de modos distintos. Os laços ativos estão presentes no cotidiano e prestam ajudas diretas. Os passivos, apesar de não envolverem uma interação rotineira, são igualmente importantes e constituem "suportes invisíveis" - as pessoas sabem que podem contar com eles quando for necessário (Portugal, 2007). Se, na população em geral, os laços ativos são essencialmente estabelecidos no interior do parentesco restrito e os passivos entre os amigos, a família alargada e, em alguns casos, os colegas (Portugal, 2014), nas pessoas que entrevistamos, os laços ativos e passivos limitam-se quase exclusivamente ao parentesco. O sentimento de isolamento social e de incompreensão é generalizado e restringe ao máximo a identificação das pessoas "com quem se pode contar".

Um traço importante para avaliar este protagonismo da família restrita é a análise das propriedades dos laços ativos. Destacam-se algumas características: em primeiro lugar, a enorme diversidade de conteúdos que circulam no seu interior; em segundo, a frequência e duração dos apoios prestados e, finalmente, a influência que os laços têm nas escolhas, decisões e comportamentos das pessoas.

A diversidade de apoios que circula no interior dos laços de parentesco restrito é sem dúvida o traço mais marcante na análise das redes sociais destas pessoas. A família presta apoio material, financeiro e em serviços, suporte afetivo e social, provê recursos instrumentais e simbólicos. A variedade de conteúdos que circula no interior das relações familiares demonstra, simultaneamente, a vitalidade dos laços de pa- 
rentesco e a sobrecarga a que está sujeita a família restrita. Apresenta, ainda, um duplo impacto na integração social das pessoas com doença mental: se, por um lado, provê recursos que deveriam potencializar a autonomia, por outro, alimenta a dependência face às relações familiares e restringe essa autonomia.

Ele ainda agora, ainda agora tem lá pão ao pé de casa e... ouça, às vezes eu estou não sei onde e ele: "Ó pai, preciso de pão. Ó pai traz-me papel higiênico" [ri-se]. É muito assim. (Aníbal, pai).

Os meus pais não me deixam sozinha. Fiz o erro [tentativa de suicídio], tenho que o pagar (Carolina).

Nas histórias e trajetórias das pessoas que entrevistamos encontramos relatos da multiplicidade de apoios prestados pela família restrita. Numa população em que a integração econômica é extremamente difícil, um dos principais apoios que provém da família restrita é o material. As ajudas financeiras em bens e em serviços revelam-se cruciais para assegurar a vida cotidiana destas pessoas. As dádivas são em dinheiro, alimentação, vestuário e bens materiais, como mobiliário e equipamento doméstico. Recursos fundamentais como a habitação e o emprego têm na família restrita o seu principal provedor. Não só grande parte dos entrevistados que não tem família conjugal habita com parentes, podendo usufruir de alojamento através do acolhimento familiar, como alguns dos que habitam sozinhos vivem em casas de familiares (emprestadas ou doadas) ou têm alojamento custeado por eles (pais e/ou irmãos).

Também no acesso ao emprego a família restrita tem um papel importante. Nos casos em que a doença se manifesta numa idade pré-ativa, a família constitui uma "almofada" para amortecer os efeitos negativos da doença em relação ao mercado de trabalho. Por um lado, quando é possível, são oferecidas possibilidades em empresas familiares; por outro, são usados os recursos relacionais para encontrar oportunidades.

Quando a doença se manifesta já num contexto de integração no mercado de trabalho, além do capital relacional ser importante para aceder a postos de trabalho, a mediação familiar é muitas vezes importante para interceder junto das entidades patronais no sentido da integração e para resolver situações de conflito laboral. 
Os laços familiares são também fundamentais no apoio à vida doméstica. Encontramos prestação de ajuda para as mais diversas tarefas: limpeza e arrumação da casa, preparação da alimentação, tratamento da roupa, tarefas de bricolage, compras, atividades de gestão doméstica (pagar contas, contratar reparações etc.). Nas situações de conjugalidade, a doença introduz, muitas vezes, uma reorganização na divisão das tarefas domésticas, com a participação do cônjuge em tarefas nas quais habitualmente não participava.

Quem cozinhava era eu. Até cinco anos atrás, quem... só havia cá uma pessoa em casa a cozinhar: era eu. Agora, deixei de cozinhar; só ela é que cozinha. Nunca se queixa; está sempre tudo bem para ela... (Vasco).

Eu dantes até tinha... Gostava de cozinhar e eles gostavam muito dos meus comeres. E eu agora nem... Olho para o fogão, não consigo. $\mathrm{O}$ meu [filho] é que faz... Nem consigo comer carne, nem consigo comer peixe. Tenho que... Não consigo. Nem todos os dias (Cândida).

Para aqueles ou aquelas que formaram uma vida conjugal e tiveram filhos, uma área importante de apoio são os cuidados das crianças. Tomar conta, levar e trazer da escola, dar refeições e banhos, ajudar nos trabalhos de casa - o envolvimento da família restrita, sobretudo em sentido ascendente, é uma constante no apoio às crianças e jovens. É importante ressaltar, no entanto, que a ajuda na guarda dos filhos, em alguns casos, traduz-se num afastamento dos filhos (crianças) e em conflitos com os familiares que prestaram essa ajuda. Isso decorre dos laços que as crianças criam com esses familiares e da incapacidade de manifestação de afetos da pessoa com doença mental quando em crise.

Assim, o apoio dos laços de parentesco para a manutenção de uma rotina diária na vida doméstica revela-se essencial para as pessoas que entrevistamos. Outro domínio em que os laços de parentesco são ativos é no apoio à trajetória clínica e nos cuidados terapêuticos. A família é, em grande medida, protagonista solitária dos cuidados, lidando com dificuldades com a aceitação e a adaptação à doença ao longo dos diferentes momentos da trajetória clínica. Desde a ocorrência dos primeiros sintomas à busca de um diagnóstico e aos percursos pósdiagnóstico, o papel desempenhado pela família é fulcral, e é no seu interior que se encontram os laços ativos na procura de respostas e soluções e na gestão da relação complexa com os sistemas de saúde e as- 
sistência social. Os relatos revelam itinerários clínicos tortuosos e mostram como os laços familiares possuem uma enorme capacidade de resiliência, procurando informação, recursos e apoio, resistindo à sua ausência e fornecendo ajuda ao familiar que dela necessita.

A família restrita é, pois, fundamental nos cuidados terapêuticos. A partir do momento em que existe um diagnóstico, é necessário assegurar contatos com o sistema médico, desenvolver terapias, tomar medicação. São os laços de parentesco que assumem este papel. O controle e administração da medicação é uma tarefa que a família apoia, a par com as outras tarefas da vida doméstica anteriormente identificadas. Esta tarefa tem um papel especialmente relevante, dado que grande parte das pessoas resiste à administração de medicação. Este é, aliás, como se verá adiante, um ponto gerador de conflitos intrafamiliares.

Sempre tomei os medicamentos de forma rigorosa. Sempre, sempre, isso sempre. Aliás, eu mesmo agora às vezes posso acordar tarde, mas a minha mãe vai à cama e vai-mos dar. Sempre, sempre. Isso é (Júlio).

E o que é que aconteceu para nunca mais ter tido internamento?

Ai é que não há pai como o meu... O meu filhinho todos os dias... antes de vir já os deixou.

Como?

O meu filhinho tem os... os medicamentos num cofre.

Num cofre?

Cofre, um cofre. Fechados. E põe-nos, os da manhã, a um lado, os da noite, ao outro. Eu então, chegando àquela horazinha vou tomá-los. E pronto, ando ali... (Felicidade).

Para além dos apoios materiais, em bens e serviços, a importância e vitalidade dos laços familiares revela-se, também, nas dimensões afetivas, relacionais e simbólicas. As relações familiares são o principal e, por vezes, único capital relacional das pessoas com doença mental. Assim, a família desempenha um papel importante na mediação da rede de relações formais e informais. Os laços de parentesco são polarizadores de relações. Por um lado, asseguram contatos com instituições e organizações formais e mobilizam laços sociais, facilitando o acesso a recursos essenciais como o trabalho, a habitação, a saúde, a segurança social. Por outro, medeiam relações com laços exteriores à família - vizinhos, colegas, amigos. Esta mediação é, sobretudo, importante quan- 
do existem conflitos, muitas vezes resultantes do desconhecimento ou da intolerância face à doença. A intervenção da família é, frequentemente, essencial para assegurar a manutenção das relações e a estabilidade das situações sociais, por exemplo, no trabalho ou na vizinhança.

Pronto. Eu aparecia sempre nas alturas difíceis, parece que me dava um toque para eu aparecer. Pronto, uma vez ele estava lá com uma crise em casa e apareceu... Havia lá um vizinho que ia chamar a GNR [Guarda Nacional Republicana] porque ele partia tudo lá em casa! Quando eu estava, segurava-o e não deixava. E então eu aparecia... Portanto, eu tentei sempre que ele não fosse traumatizado. Eu tentei sempre que... que ele não ficasse envergonhado, que não fosse traumatizado. Pronto, porque [ele] tem uma vida lá fora, ele não está nada traumatizado do que fez, dos espetáculos que fez! [rindo-se] Eu ainda tenho a casa lá toda partida, porque deixei estar para ele ver móveis que ele... Bastava eu dizer-lhe que não ou exigir alguma coisa para ele partir logo tudo. Pronto, passámos uma fase assim (Aníbal, pai).

Um domínio no qual é importante destacar o apoio da família restrita é o emocional. É nos laços de parentesco que encontramos os laços fortes e positivos das pessoas com doença mental. Apesar de todas as dificuldades e conflitos, é na família que estas pessoas encontram apoio afetivo. A incompreensão para os seus problemas e a falta de comunicação com os outros são características da vida destas pessoas, que reduzem suas redes aos laços familiares, ao mesmo tempo que encontram neles a única fonte de compreensão e suporte afetivo.

Finalmente, algumas observações acerca da relação entre a diversidade dos apoios prestados e a orientação da rede. Se a multiplicidade de apoios é uma característica dos laços de parentesco restrito, e a sobreposição de conteúdos nos laços uma constante, nota-se, no entanto, uma orientação diversa da rede em função do tipo de apoios. Assim, enquanto o apoio material é sobretudo prestado pelos laços verticais ascendentes e marcado por uma forte matrilinearidade, o apoio emocional sustenta-se nos laços horizontais - irmãos e irmãs.

Ela [mãe] foi mesmo uma leoa a cuidar da sua cria e a querer que eu continuasse e que terminasse os estudos. E a última cadeira que eu fiz foi com a ajuda dela, já. Ela... ela pegou-me nos apontamentos que eu tinha das aulas e no livro e começou a estudar Direito Civil comigo. E falávamos alto uma com a outra e... foi assim. O último exame já foi nestas tristes condições, nesta... Ela que era de uma área completamente diferente a... a envolver-se nas cadeiras de Direito para ver se eu conse- 
guia fazer os exames. E depois fui à oral, fui à oral nesse... fui à escrita, tirei seis, não tirei uma nota muito boa, mas foi porque... por falta, falta de atenção da minha parte. Porque eu errei um caso prático que podia muito bem... Se tivesse mais atenção, podia ter acertado. E por isso fui à oral. Mesmo na oral ela foi comigo a... à faculdade, estava cá fora à espera e tudo, para eu me sentir mais segura, para eu me sentir mais apoiada e falava com os outros... os outros que já tinham feito a oral e... e tudo, pronto. Correu lindamente a oral, mas eu disse que já estava esgotada, completamente esgotada e que não podia continuar. Não tinha condições de continuar (Iolanda).

Já me zanguei muitas vezes e... mas... a partir de certa idade comecei a pensar que não vale a pena a gente zangar-se, não... E de certa forma, eu até... e é um agradecimento que eu tenho em relação a eles [irmãos]... Depois de a minha doença ser identificada, reuniram-se todos um pouco à minha volta. E é uma grande... Deram provas de grande união... de grande união familiar e... e eu estou muito agradecido [...].

Mas esse [irmão] será aquele com que sempre esteve mais ligado?

Sim, sim, será. E, hoje em dia, nós temos o mesmo espaço de trabalho e vemo-nos quase todos os dias. E ele ajudou-me muito aqui, quando fui ao Lorvão... Tive mais um episódio de... uma crise da minha doença e ele ajudou-me. Foi incansável. Ajudou-me muito. Porque ele... O outro, ele mora cá em Coimbra, saiu assim um pouco da coisa. Porque tem a vida muito ocupada e assim. Foi ele que, coitado, tratou da minha mudança de casa, tudo. Foi ele que... Ajudou-me muito mesmo (Alberto).

Uma característica que encontramos nas redes de algumas das pessoas entrevistadas relativa à sobreposição de conteúdos nos laços é a concentração de apoios num só elemento da rede. Por vezes, mesmo em redes de dimensão elevada, onde existe um considerável número de laços potencialmente ativos, apenas um nó presta apoio, desempenhando diversos papéis e fornecendo suporte a diferentes níveis. A concentração do apoio num único membro da família decorre sobretudo de dois tipos de situações: da opção do próprio familiar, que não quer perturbar o resto da família e do afastamento deliberado do resto da família, que não quer ou não tem condições para se envolver.

\section{AS TEIAS QUE A DOENÇA TECE (I)}

A rede de relações sociais das pessoas com doença mental tem uma importância fundamental na configuração das maneiras de entender e 
lidar com a doença. A morfologia da rede influi na percepção dos problemas, na definição das situações e nos itinerários terapêuticos.

A rede é a primeira receptora dos sinais iniciais da doença, quando ela ainda não é percebida como tal. A família, os amigos e os vizinhos são quem lidam com os primeiros sintomas - alterações comportamentais, atitudes anômalas, problemas relacionais. Do entendimento desses sinais dependerá, muitas vezes, a trajetória terapêutica da pessoa com doença mental. O trabalho de campo mostrou que, na maioria dos casos, decorre um longo período de tempo entre o surgimento das primeiras manifestações da doença e o seu diagnóstico.

Esse hiato de tempo, em muitos casos, chega a durar vários anos.

A minha doença foi-me diagnosticada muito depois de ela aparecer. $\mathrm{Ou}$ seja, ela apareceu-me tinha 29 anos e vivi sete anos para aí, sete, oito anos...

...sem saber que a tinha?

...sem saber que a tinha.

Sem ser tratado...?

Exato. E a lutar contra ela no dia a dia numa luta enorme. E a trabalhar e assim. Era uma luta enorme! E depois tive um episódio mais violento e os médicos então acabaram por me diagnosticar a doença (Alberto).

Comportamentos dos mais variados tipos, que vão desde a apatia, mais ou menos profunda, passando pela fobia ao contato social e pelo complexo de perseguição, até a agressividade verbal ou física, não são reconhecidos, pela família e pela própria pessoa, como sintomas da existência de uma doença psiquiátrica. A tendência de muitas famílias, durante esta fase inicial, é a de justificar as atitudes da pessoa com argumentos que não questionam a sua saúde mental, mas, antes, a sua personalidade, os hábitos adquiridos, a educação recebida e o contexto familiar e social envolvente. Quando esses comportamentos ocorrem durante a adolescência ou juventude, essas justificações tendem ainda a ser enquadradas e reforçadas com os argumentos de "excentricidade própria da idade", "más influências" ou "más companhias".

A doença foi detectada em Lisboa, há aproximadamente 10 anos, salvo erro. [...] Até lá, pronto... Portanto, foi quando ele de fato teve uma primeira atitude que foi... que foi... que serviu para... para... para detectar a doença, pronto... A atitude pública, vá lá... pessoal e pública... 
que permitiu essa leitura, ou esse diagnóstico. Até lá, nós, independentemente da classificação de feitios, por atitudes que teria, uma ou outra de vez em quando, nunca reconhecemos isso como uma doença, muito menos uma doença psiquiátrica, e uma esquizofrenia. [...] Era uma pessoa muito... muito persistente, tinha... Pronto, mas eu não vou... não vou... não... Ou seja, não me cabe a mim, não consigo... Nem consigo dizer que eram sintomas da esquizofrenia, até porque eu hoje vejo quando ele está em estado... mais descontrolado, [quando] não está tão calmo..., pronto, há alguns sintomas da doença, e eu vejo que... associo a muitas atitudes que ele já tinha antes de ser... diagnosticado... (Simão, irmão).

Ele já nessa altura [refere-se à fase das primeiras manifestações da doença] tinha editado... já tinha ganhado um prêmio qualquer ligado à poesia, com uma edição num livro... num livro e, portanto, porque era um poeta e, portanto, como era um poeta... Porque tudo era válido... tudo era válido... era poeta [risos]. E como nós temos esses... esses padrões... esses mitos [risos] de que a arte está ligada à loucura e ao... ao estranho e... e ao menos... e ao anormal..., aquilo... aquilo para mim era... com certeza fazia parte e, portanto, ele era assim e eu não era nada assim, eu... eu era o oposto, era muito certinho, aliás, a forma como... como a minha vida progrediu foi... foi... foi mesmo a diferença total, o outro lado... o outro lado, os 180ํ, não é? (Henrique, irmão).

Os dois irmãos, uma irmã mais nova e um irmão mais velho, que na altura viviam os três com a mãe, também [não conseguiam] compreender aquela problemática, porque a doença mental para eles é uma realidade completamente desconhecida, e consideravam mais a hipótese da droga, aliás mais gente, até a própria mãe, e falta de disciplina, a falta do pai, ausente há uns anos lá de casa (Afonso, pai).

A dificuldade em reconhecer os comportamentos invulgares como sintomas de uma doença é tanto maior quando se associam à doença ( $a$ priori ou a posteriori) problemas com drogas ou com álcool. Nesses casos, a dificuldade de reconhecimento decorre, em grande medida, do predomínio de uma explicação aparentemente óbvia, que descarta a procura de outras explicações para a mudança de comportamento da pessoa e, por consequência, a procura de soluções não direcionadas para o tratamento dessas dependências. Com efeito, nestes casos, é frequente que os esforços da família sejam canalizados durante longos anos para esse tipo de terapia, sendo que os resultados, quando existem, tendem a ser temporários. 
Pronto, eu nunca tive a noção de que ele tinha esquizofrenia! Eu nunca tive, porque eu vi-o sempre normal. Ele fazia esses distúrbios, mas no resto era normal sempre! Ele fazia... Quando... quando fazia alguma coisa, fazia bem... Ele quando estudava, estudava bem... Pronto, eu nunca... eu nunca quis acreditar que ele tivesse essa doença. Que tivesse essa... a esquizofrenia... [Os distúrbios que ele fazia] associei sempre... sempre mais... à droga e não à doença... [Uma vez apanhei-o] a comprar droga... foi quando a polícia me chamou lá abaixo. Foi aí que nós tivemos a certeza que de fato que ele se metia na droga. E a partir daí tentamos a desintoxicação e... e nunca mais se deixou de ter tratamento. Nunca mais se deixou de ter tratamento. Foi aí até os 24, 25 anos, foi tratamento só antitóxicos quanto... quanto à droga (Aníbal, pai).

As famílias produzem uma normalização da desordem produzida pelos sintomas da doença, sustentada em justificações que sobrevalorizam as características da personalidade, a socialização, e os contextos envolventes. A "naturalização" dos comportamentos da pessoa doente leva a que estes deixem progressivamente de ser encarados como invulgares para passarem a ser vistos como parte integrante do dia a dia.

Esta adaptação da família às primeiras manifestações da doença resulta em dois tipos diferenciados de estratégias: a passividade e inação, sem a tomada de qualquer tipo de medidas, e a ação desadequada, resultante do desconhecimento e da impotência perante os problemas e que, não raras vezes, potencializa efeitos negativos, designadamente, a agudização da situação clínica, dos conflitos entre a pessoa doente e a família e da sobrecarga familiar.

\section{AS TEIAS QUE A DOENÇA TECE (II)}

A doença tem também efeitos na rede, que se fazem sentir desde os primeiros sintomas. Como vimos, através da identificação dos nós e dos laços, a doença mental produz um fechamento das redes sociais que começa antes do seu diagnóstico, mas que se intensifica com este, rompendo com muitas das relações anteriormente estabelecidas. O eclodir da doença condiciona fortemente os laços relacionais dos indivíduos, restringindo as suas sociabilidades e limitando as suas possibilidades de apoio social e afetivo. As entrevistas permitem identificar alguns traços das redes sociais fortemente marcados pelos efeitos do estigma social que reveste a doença: em primeiro lugar, a reduzida dimensão e densidade das redes; em segundo, a sua orientação para os laços de pa- 
rentesco e, especificamente, para o parentesco restrito. E, ainda, cabe destacar que, no interior da família restrita, as mulheres são as grandes polarizadoras das relações e por quem passa a articulação entre diferentes laços e apoios.

A escassez de nós na rede e a centralidade do parentesco restrito relacionam-se com outra característica - a forte sobreposição de papéis dos elementos da rede, traduzida, especialmente numa forte sobrecarga familiar no enfrentamento da doença. Esta deve-se, principalmente, a um outro traço das redes - sua segmentação. Sobretudo entre redes formais e informais, encontramos ausências de interação e articulação que prejudicam a inserção social e a autonomia dos indivíduos.

O fechamento social começa com a eclosão dos primeiros sintomas. A família mantém os sobressaltos cotidianos sob reserva e tenta preservar uma aparência de ordem perante a desordem vivida, não a partilhando com elementos exteriores ao núcleo familiar restrito. Conforme os relatos indicam, o fechamento da família sobre si mesma constitui-se em uma estratégia de enfrentamento perante a incompreensão e intolerância de quem se encontra do lado de fora.

Podemos identificar nas pessoas entrevistadas uma "identidade social deteriorada" (Goffman,1982), resultante de estereótipos negativos e de reações sociais adversas, que marcam a pessoa como diferente, indesejável e, em casos extremos, perigosa, influenciando negativamente a identidade pessoal e social e as relações interpessoais.

As pessoas aqui tinham medo de me ver a andar. Aqui na aldeia. As pessoas viam-me na rua com os olhos assim muito arregalados e a andar assim com o corpo... Não conseguia com o corpo... As pessoas tinham medo de mim. Viam-me... Pronto, não era uma pessoa normal. A andar estava mesmo... mesmo acabado. As pessoas diziam à minha esposa: "O teu homem está mesmo... mesmo...". Andava mesmo, mesmo em baixo (Francisco).

A evolução da doença, sem qualquer tipo de acompanhamento terapêutico, agrava os sintomas e gera comportamentos disruptivos com profundos efeitos negativos na esfera relacional. O campo profissional é uma área na qual se podem verificar os fortes impactos da doença na inserção social das pessoas. A perda do emprego ou a incapacidade para desenvolver uma ocupação são uma das repercussões das manifestações da doença. 
Fui ajudante de motorista numa firma de entrega de gás ao domićlio. E... [pausa prolongada] estive lá até me ser diagnosticada a doença. Até muito tarde, passei lá sete anos, sei lá, ou que foi... Sete anos, não... cinco, seis. Cinco, seis, talvez. [...] Aliás, não... Espere lá. Eu já não me lembro das datas... Mas pronto, ainda lá trabalhei alguns anos, nessa firma. Porque eu, primeiro, fui ajudante de motorista, depois fui para motorista mesmo. E andava sozinho praticamente. Era. Na carrinha. E fazia de motorista e de ajudante. E pronto, passei lá muitos anos até me ser diagnosticada a doença [em 1999], tinha eu 35 anos ou coisa assim do gênero. Portanto, passei... 35, 36. Pronto, passei dos 29 aos 36 sem estar medicado, sem nada; sem apoio, sem orientação médica. Desde os 29 até aos 36. Isso numa... Tornava-me conflituoso. Eu abandonei o trabalho porque estava a ser muito conflituoso, abandonei o trabalho (Alberto).

A minha mãe... Ela chegou a abrir aqui [em nossa casa] um salão de estética. E... e pronto, começou a discutir com as clientes e elas começaram com conversas e diálogos estranhos e... só histórias tristes, pronto... Eu chegava a casa e depois as pessoas falavam comigo: "Olha que a tua mãe não...". E eu: “Bom, não é possível...". Porque a minha mãe dizia que não. A minha mãe, eu acreditava sempre nela. E nem é acreditar... E depois eu não queria acreditar que a minha mãe... "A minha mãe assim, é impossível...". E não sei quê, e pronto... Mas pronto... Só comecei mesmo a ver que a minha mãe estava completamente doente... há quatro, cinco anos para cá é que a minha mãe descambou completamente. As conversas com as clientes... As pessoas pensavam que estavam a falar com uma pessoa normal, que a minha mãe era... só que começavam a ter uma conversa e a minha mãe quando tem a mania que tem razão... Ui [risos]! Depois era discussões, e ela tratava-as mal, e essas coisas (André, filho).

O diagnóstico da doença e o desenvolvimento de uma trajetória clínica não contribuem para a redução dos impactos negativos no domínio relacional. Pelo contrário, o diagnóstico atribui um rótulo definitivo, com profundos impactos na morfologia das redes sociais. Os internamentos ou o acompanhamento clínico no hospital psiquiátrico contribuem decisivamente para a estigmatização das pessoas com doença mental e o seu isolamento social. "As pessoas quando souberam que eu andava no Sobral Cid [hospital psiquiátrico], às vezes ouvia bocas. Uma vez um até... me quis bater e tudo por eu me sentar numa mesa 
num café: 'ai, o que é que está aqui a fazer, seu anormal e não sei quê'”' (Ricardo).

Produz-se, assim, um processo de fechamento no espaço doméstico, de redução do capital relacional e de perda de autonomia e de independência, o que aumenta a sobrecarga e a tensão no interior da família, cria condições favoráveis ao agravamento da doença e tem efeitos gravosos na inserção social das pessoas.

\section{AS TEIAS QUE A DOENÇA TECE (III)}

\section{A família faz-me a vida num inferno (Fernanda)}

O papel preponderante da família na prestação de apoio não pode ser olhado sem considerar os problemas que daí advêm. As elevadas exigências e desafios que a doença mental impõe à vida familiar potencializam conflitos, quer entre a pessoa com doença mental e os seus familiares, quer entre estes.

Os atritos entre a pessoa doente e os familiares prendem-se sobretudo a questões relativas à autonomia e ao respeito das suas opções e da sua subjetividade. As pessoas entrevistadas queixam-se frequentemente das suas famílias enquanto "aliadas dos médicos" na imposição de terapias que recusam - consultas psiquiátricas, internamentos hospitalares, medicação. O apoio recebido da família nem sempre coincide com as necessidades sentidas e, muitas vezes, colide com os desejos de quem o recebe. Na procura de soluções para os problemas, na busca de diagnósticos e de respostas terapêuticas, as diligências tomadas e as estratégias desenvolvidas pelas famílias são múltiplas, nem sempre bem informadas, e, algumas vezes, duvidosas do ponto de vista ético. A intervenção familiar, por vezes sustentada no desespero, vem a se chocar frequentemente com a vontade e os direitos de quem adoece, e é geradora de conflitos e rupturas.

Portanto, houve uma fase em que a minha mãe ia lá à casa [da irmã doente] todos os dias dar-lhe o jantar e pôr-lhe umas gotas que aconselharam a pôr-lhe, a ver se, pronto, se ela... Punham-lhe na sopa para ver se ela ficava mais lúcida... Foi o que foi aconselhado pelo médico de família. Ela não sabia. Portanto, mas mesmo assim, quando desconfiou não quis mais a ajuda da minha mãe, não quis... não quis ir ao médico, deixou de ir a casa dos meus pais. Ela não entrava em casa dos meus pais (Clara, irmã). 
Era sempre [o meu pai] que lidava com os médicos. Com... com os médicos, com a medicação... Havia vezes que... Isto é confidencial... Houve medicação que o meu irmão tomou sem saber. Era o meu pai que lá lhe... colocava a medicação na comida ou o que fosse. Na sopa... [risos]. [...] Já não me lembro por que razão era... que houve essa necessidade, de lhe dar medicamentos sem ele saber. Mas já não me lembro porquê. Não sei se era ele que se sentia... Hum, não sei... Que sentia algum efeito que não gostava e não queria tomar... (Teresa, irmã).

Quanto aos conflitos entre familiares, de um modo geral, no interior do parentesco restrito, eles são mais comuns entre irmãos do que entre pais e filhos. No entanto, as divergências e conflitualidades entre irmãos passam também pelas relações entre pais e filhos, pela forma como os pais lidam com a doença do filho ou da filha, pelo modo como os pais estruturam dádivas e obrigações para os diferentes filhos e pela maneira como foi realizada a socialização familiar de uns e de outros. As necessidades de apoio da pessoa com doença mental exigem dos pais uma dedicação que coloca em causa o princípio da igualdade que preside as relações intergeracionais. A desigualdade é causa de conflito entre irmãos e entre pais e filhos.

É possível identificar dois motivos principais de conflito no interior da família: um prende-se com o conhecimento da doença, a sua aceitação e a compreensão das suas consequências; o outro, com as necessidades de apoio das pessoas com doença mental.

Em relação ao primeiro fator, por um lado, a falta de informação e de conhecimento sobre a doença mental, os seus sintomas e as suas consequências levam a sentimentos e atitudes de incompreensão e intolerância por parte dos familiares. Por outro lado, a doença induz comportamentos disruptivos para a vida familiar que as pessoas doentes recusam reconhecer e, muitas vezes, combater. Estas duas facetas do mesmo problema são geradoras de fortes conflitos e conduziram, em vários dos casos analisados, a situações de afastamento e ruptura.

Quanto ao segundo fator, das necessidades de apoio das pessoas com doença mental, estas sujeitam a família a enormes pressões, geram sobrecargas e criam desigualdades entre os diferentes elementos da família. Por um lado, a multiplicidade de papéis que os laços ativos desempenham leva a um esgotamento físico e psicológico que potencializa o conflito. Por outro, a desigualdade existe, quer ao nível da prestação de apoio, por exemplo, fortemente penalizadora para as mu- 
lheres, quer das relações intergeracionais e do sentimento de injustiça sentido por alguns irmãos face ao apoio que os pais prestam à pessoa com doença mental.

\section{REDES SOCIAIS E DOENÇA MENTAL: ALGUMAS PISTAS DE REFLEXÃO}

Este artigo pretende mostrar a importância de uma análise reticular para: 1) compreender as trajetórias sociais e clínicas das pessoas com doença mental e 2) conhecer as potencialidades e constrangimentos das redes sociais para a prestação de cuidados num contexto de desinstitucionalização da doença mental.

Ao contrário de uma abordagem estática e sincrônica que muitas vezes encontramos na análise de redes, a pesquisa empírica apresentada procurou uma perspectiva dinâmica, que seguiu as trajetórias dos indivíduos e identificou necessidades e apoios, problemas e respostas ao longo das suas histórias de vida pessoais e familiares.

O estudo mostrou a reduzida dimensão e densidade das redes sociais das pessoas com doença mental. A doença produz um fechamento das redes que começa antes do seu diagnóstico, mas que se intensifica com este, rompendo com muitos dos laços anteriormente estabelecidos. $\mathrm{O}$ eclodir da doença condiciona fortemente os laços relacionais dos indivíduos, restringindo as suas sociabilidades e limitando as suas possibilidades de apoio social e afetivo.

Os apoios surgem, sobretudo, no interior dos laços de parentesco e, especificamente, do parentesco restrito - pais, cônjuges, irmãos, filhos. A escassez de nós na rede e a orientação para o parentesco restrito traduz-se numa forte sobrecarga familiar no enfrentamento da doença. Apesar da enorme capacidade de resposta e vitalidade que os laços de parentesco revelam, a ausência de mecanismos de suporte que capacitem as famílias para o cuidado tornam as suas respostas frágeis.

Por um lado, o isolamento social e a centralização nos cuidados esgotam as famílias reduzindo, ao longo do tempo, a sua capacidade de resposta; por outro, o apoio familiar traduz-se, por vezes, em mecanismos de proteção e controle das pessoas com doença mental que, ao invés de promoverem a sua autonomia e integração social, sustentam mecanismos de dependência e reduzem os seus círculos sociais.

Como outros trabalhos têm sublinhado, a implicação da família no cuidado da doença mental é uma "consequência mecânica" das políti- 
cas de desinstitucionalização (Bungener, 2001; Carpentier, 2001). A ausência de outras fontes de apoio obriga a família a responder continuamente a uma enorme diversidade de necessidades materiais e emocionais que conduzem ao esgotamento físico e psicológico. $\mathrm{O}$ apoio familiar, sendo de uma enorme diversidade e plasticidade, é também de uma enorme fragilidade e vulnerabilidade, constantemente ameaçado pelas dificuldades materiais e emocionais, amplificadas pelo desgaste imposto com o passar do tempo, do envelhecimento, do cansaço, das exigências de um cuidado continuado, permanente e de longa duração.

Em Portugal, as políticas de desinstitucionalização têm tido como garantia o cuidado familiar (Hespanha et al., 2012). Neste, como em outros contextos, ele é imposto pela ausência de estruturas alternativas, e as famílias têm o sentimento do seu papel ser desconhecido, ou mesmo negado, pelo sistema de saúde (Bungener, 2001). Assim, urge, por um lado, tomar as famílias como parceiras, e por outro, ampliar a rede de cuidados e em alternativas na comunidade que apoiem as pessoas com doença mental e suas famílias.

A abordagem a partir das redes sociais permite identificar três tarefas-chave para o sucesso das políticas de desinstitucionalização: informar, educar e democratizar.

A informação e educação sobre a doença mental para a população em geral e para os técnicos e profissionais das áreas sociais e da saúde, em particular, é fundamental para que, por um lado, o estigma social se reduza e, por outro, exista um reconhecimento precoce da doença. Uma maior capacitação para identificar previamente a doença e "saber como agir" contribuirá para que não se chegue a situações de grande desestruturação da vida pessoal e familiar, sejam providenciados cuidados de maior qualidade e se reduzam obstáculos sociais à integração.

Finalmente, é necessário democratizar o modelo de cuidados da doença mental, transformando os indivíduos e as famílias em parceiros dos processos. Para que exista uma efetiva inclusão das pessoas com doença mental é preciso que elas não sejam meros objetos de intervenção, mas, sim, sujeitos com capacidade de decisão sobre as suas trajetórias. Para tal, é fundamental capacitar as famílias e formar técnicos e profissionais. É mister superar um modelo biomédico fechado e fazê-lo evoluir no sentido de incorporar as dimensões psicológicas, sociais, am- 
bientais, simbólicas e outras que envolvem o adoecer mental. É preciso assumir que o trabalho multidisciplinar, a diversidade de respostas e a articulação entre atores, formais e informais, são elementos-chave para a promoção da inclusão social e da autonomia das pessoas com doença mental.

(Recebido para publicação em janeiro de 2014) (Aprovado para publicação em maio de 2014) 


\section{NOTAS}

1. "A Desinstitucionalização da Doença Mental. O Papel das Redes Sociais nos Cuidados de Saúde", coordenada por Pedro Hespanha no Centro de Estudos Sociais da Universidade de Coimbra e financiada pela Fundação para a Ciência e Tecnologia (FCT PTDC/SDE/65653/2006). A pesquisa deu origem à publicação Hespanha et al. (2012).

2. Hospital Sobral Cid (HSC), situado na cidade de Coimbra, região central de Portugal. Criado em 1945, este hospital encontrava-se na época do estudo em processo de desinstitucionalização no âmbito de uma reforma estrutural dos serviços de saúde mental portugueses.

3. Foram entrevistadas 12 pessoas em regime de internamento (seis na Clínica de Agudos e seis no Hospital de Dia) e oito em regime de ambulatório (três no Hospital de Dia e cinco nas consultas externas). Os doentes crônicos residentes não foram entrevistados. A situação de internamento permanente foi analisada através do recolhimento de informação documental e da observação direta, e não é objeto de análise neste artigo.

4. Foram realizadas oito entrevistas com pessoas com diagnóstico de esquizofrenia, 10 entrevistas a pessoas com diagnóstico de doença bipolar e duas entrevistas a pessoas com um diagnóstico indefinido entre esquizofrenia e bipolar.

5. Estas últimas foram analisadas em outro lugar (Hespanha et al., 2012: cap. 2).

6. A abordagem egocentrada reconstitui a rede de relações de um determinado indivíduo (ego); neste caso, a pessoa com doença mental. As "redes egocentradas" (egocentric networks) são definidas, pela maioria dos autores, como o conjunto de indivíduos que conhecem e interagem com um determinado "alvo" (Milardo, 1988). 


\section{REFERÊNCIAS BIBLIOGRÁFICAS}

BUNGENER, Martine. (2001), “Vivre Hors les Murs de l'Hôpital Psychiatrique: Le Role Incontournable de la Famille en ce Début de Siècle". Sciences Sociales et Santé, vol. 19, no 1, pp. 107-111.

CARPENTIER, Normand. (2001), "Le Long Voyage des Familles: La Relation entre la Psychiatrie et la Famille au Cours du XXème Siècle". Sciences Sociales et Santé, vol. 19, no1, pp. 79-106.

DEGENNE, Alain e FORSE, Michel. (1994), Les Résaux Sociaux. Paris, Armand Colin.

FONTES, Breno e PORTUGAL, Sílvia. (2013), “A Análise das Redes Sociais: O Caso da Saúde Mental”, in F. Alves (org.), Saúde, Medicina e Sociedade. Uma Visão Sociológica. Lisboa, Pactor, pp. 179-202.

GOFFMAN, Erving. (1982), Estigma, Notas Sobre a Manipulação da Identidade Deteriorada. Rio de Janeiro, Jorge Zahar Editor.

(2001), Manicômios, Prisões e Conventos (7a ed.). São Paulo, Editora Perspectiva.

GRANOVETTER, Mark S. (1973), “The Strength of Weak Ties”. American Journal of Sociology, vol. 78, no 6, pp. 1360-1380.

. (1982), “The Strength of Weak Ties: ANetwork Theory Revisited", in P. V. Marsdene N. Lin (eds.), Social Structure and Network Analysis. Beverly Hills, Sage, pp. 105-130.

HESPANHA, Pedro et al. (2012), A Desinstitucionalização da Doença Mental. Coimbra, Almedina.

LEMIEUX, Vincent. (1999), Les Réseaux d'Acteurs Sociaux. Paris, PUF.

MERCKLÉ, Pierre. (2004), Sociologie des Réseaux Sociaux. Paris, La Découverte.

MILARDO, Robert. (1988), “Families and Social Networks: An Overview of Theory and Methodology", in R. Milardo (ed.), Families and Social Networks. Newbury Park, Sage, pp. 13-47.

PORTUGAL, Sílvia. (2007), “Contributos para uma Discussão do Conceito de Rede na Teoria Sociológica". Oficina do CES, no 271.

. (2014), Família e Redes Sociais: Ligações Fortes na Produção de Bem-Estar. Coimbra, Almedina.

SIMMEL, Georg. (1955), Conflict \& the Web of Group-Affiliations. New York, The Free Press.

WASSERMAN, Stanley e FAUST, Katherine. (1999), Social Network Analysis. Methods and Applications. Cambridge, Cambridge University Press.

WELLMAN, Barry. (1985), "Studying Personal Communities", in P. V. Marsden e N. Lin (eds.), Social Structure and Network Analysis. Beverly Hills, Sage, pp. 61-103. 


\section{RESUMO}

As Teias que a Doença Tece: A Análise das Redes Sociais no Cuidado da Doença Mental

Este artigo pretende mostrar a importância de uma análise das redes sociais para compreender as trajetórias sociais e clínicas das pessoas com doença mental e conhecer as potencialidades e constrangimentos de ditas redes para a prestação de cuidados num contexto de desinstitucionalização da doença mental. Com base nas histórias de vida de vinte pessoas com doença mental e de sete estudos de caso realizados no interior desse grupo em Portugal, identificam-se os nós e os laços das suas redes sociais, mapeando-se atores e tipos de apoio disponíveis. $\mathrm{O}$ artigo revela a vitalidade e a capacidade de resposta da rede familiar, mas mostra também as dificuldades materiais e emocionais enfrentadas, as fragilidades do apoio prestado pela família e as limitações à autonomia e inclusão social das pessoas com doença mental.

Palavras-chave: doença mental; redes sociais; desinstitucionalização; cuidado; família

\section{ABSTRACT \\ How Disease Weaves Webs: An Analysis of Social Networks in Mental Illness Care}

This article seeks to demonstrate the importance of social network analysis in order to understand the social and clinical trajectories of people with mental illnesses, and also to apprehend the potential and constraints of said networks for caregiving in a context of de-institutionalization of mental disease. Based on the life stories of twenty people with mental illnesses and seven cases studies within this group in Portugal, the investigation identified the knots and ties of their social networks, mapping actors and types of support available. The article reveals the vitality and response of family networks, yet it also reveals the material and emotional difficulties, the fragility of family-provided care and the limitations to the social inclusion of people with mental illness.

Keywords: mental illness; social networks; de-institutionalization; caregiving; family 


\section{RÉSUMÉ}

Les Toiles qui Tisse la Maladie: L'Analyse des Réseaux Sociaux dans les Soins de la Maladie Mentale

Cet article vise à montrer l'importance d'une analyse des réseaux sociaux pour comprendre les trajectoires sociales et cliniques des personnes atteintes de maladie mentale et de connaître les potentialités et contraintes de ces réseaux pour la prestation de soins dans un contexte de désinstitutionalisation de la maladie mentale. Basé sur les histoires de vie de vingt personnes atteintes de maladie mentale et sept études de cas au sein de ce groupe au Portugal, sont identifiés les nœuds et les liens de ces réseaux sociaux, en cartographiant les acteurs et les types de soutien disponibles. L'article révèle la vitalité et la réactivité du réseau familial, mais montre également les difficultés matérielles et émotionnelles rencontrées, les faiblesses du soutien donné par la famille et les limites à l'autonomie et l'inclusion sociale des personnes ayant une maladie mentale.

Mots-clés: maladie mentale; réseaux sociaux; désinstitutionalisation; attention; famille

\section{RESUMEN}

Los Hilos Tejidos por la Enfermedad: El Análisis de Redes Sociales en el Cuidado de la Enfermedad Mental

Este artículo pretende mostrar la importancia de un análisis de redes sociales para comprender las trayectorias sociales y clínicas de las personas con enfermedad mental y conocer las potencialidades y limitaciones de dichas redes para la prestación de cuidados en un contexto de desinstitucionalización de la enfermedad mental. Apoyado en las historias de vida de veinte personas con enfermedad mental y en siete estudios de caso realizados en el interior de este grupo en Portugal, se identifican los nudos y los lazos de las redes sociales, mapeándose actores y tipos de apoyos disponibles. El artículo revela la vitalidad y la capacidad de respuesta de la red familiar, pero también recalca las dificultades materiales y emocionales enfrentadas, las fragilidades del apoyo prestado por la familia y las limitaciones a la autonomía e inclusión social de las personas con enfermedad mental.

Palabras clave: enfermedad mental; redes sociales; desinstitucionalización; cuidado; familia 